\title{
Formação do professor de história no Brasil: embates e dilaceramentos em tempos de desassossego
}

The history teacher formation in Bazil: fights and dilacerations in times of unquietness

\author{
Maria Auxiliadora Moreira dos Santos Schmidt* \\ Universidade Federal do Paraná
}

Resumo No Brasil ocorre uma ênfase em políticas voltadas para a formação de professores, inclusive professores de História, em que a centralidade do debate está no binômio educação e desenvolvimento. Nesse debate, a personagem que tem sido mais destacada é o professor. $\mathrm{O}$ presente trabalho tem como foco apresentar uma síntese das propostas para a formação do professor de História no Brasil, a partir de documentos oficiais. A análise dos documentos teve como referência teórica as questões que envolvem a relação entre a formação fundamentada na epistemologia da prática e a formação fundamentada na epistemologia da práxis. Resultados dessa análise indicam o esvaziamento da formação teórica, da valorização dos conteúdos específicos, em detrimento de uma formação prática, que não leva em consideração a relevância da função social da educação e a finalidade da História para a formação do cidadão crítico.

PALAVRAS-CHAVE: Consciência histórica; Aprendizagem histórica;

Formação de professores.

Abstract In Brazil, there is currently an emphasis in policies aimed at teachers' formation, including history teachers, in which the centrality of the debate is in the education and development binary. At this debate, the most highlighted character is the teacher. The present paper focuses on presenting a summary of the proposals for the history teacher formation in Brazil, arising from the educational policies. The documents' analysis had, as a theoretical reference, the questions involving the relation between the formation grounded in the epistemology of the practice and the one based on the praxis epistemology. Outcomes of this analysis indicate the disappearance of theoretical formation, the value of the specific contents, to the detriment of a practical formation, which does not take into consideration the relevance of the education social function and the aim of History for the formation of a critical citizenship.

KEYWORDS: Historical consciousness; Historical learning; Teachers' formation. 


\section{Pois o bistoriador que pesquisa, é um não-professor? \\ E o professor que ensina, é um não historiador?}

As indagações que dão origem a esse texto têm constituído parte de minha trajetória como historiadora, professora e pesquisadora. Desde os percursos cotidianos na escola básica e na Universidade, e nessa última em face das múltiplas indagações de colegas historiadores sobre se eu havia desistido de ser historiadora, quando, ao mudar do Departamento de História para o de Educação, passei a me dedicar, exclusivamente, às temáticas do ensino de História. Já como professora universitária, em 1996, durante o $2^{\circ}$ Encontro Perspectivas do Ensino de História, realizado na USP, participei de uma mesa redonda na qual levantei algumas questões sobre o trabalho do professor. Essa apresentação foi publicada com o título $A$ formação do professor de história e 0 cotidiano da sala de aula (BITTENCOURT, 1998). Nesse texto, estão registradas ressonâncias dos dilaceramentos e embates das discussões que, à época, se faziam sobre a formação do historiador professor e que envolvem experiências relacionadas à sua profissão, ao mesmo tempo que se anuncia um horizonte de expectativas, quando é assumido o pressuposto de que

ciente do conhecimento que possui, o professor de história pode oferecer a seu aluno a apropriação do conhecimento histórico existente, por meio de um esforço e de uma atividade com a qual ele retome a atividade que edificou esse conhecimento. É também o espaço em que um embate é travado diante do próprio saber: de um lado, a necessidade do professor ser o produtor do saber, de ser partícipe da produção do conhecimento histórico, de contribuir pessoalmente. De outro lado, a opção de tornar-se apenas um eco do que os outros já disseram. (SCHMIDT, 1998, p. 57).

Em síntese, requeria-se à formação do historiador professor, um sólido conteúdo científico, um consistente preparo de pesquisador, teórico e prático, envolvendo o compromisso político de transformá-lo significativamente na relação com a práxis, não com a prática em si mesma, mas com o mundo real, concreto e histórico de si mesmo e dos seus alunos.

No entanto, faltava a essa reflexão tomá-la na objetividade da própria história. Ou seja, a pergunta ausente foi - por que a construção dessas tensões e dilaceramentos ressoava na experiência e na formação do historiador professor? Uma década e meia após, arriscaria algumas hipóteses e uma pequena tese. As hipóteses poderiam iniciar-se com: a - Os dilaceramentos existentes na formação do historiador/professor são produtos históricos da divisão do trabalho existente na sociedade capitalista e que redundam na existência daquelas que produzem e daqueles que transmitem a própria ciência. Como decorrência, historicamente, a produção do conhecimento histórico tornou-se privilégio de determinados sujeitos e espaços, como a academia, promovendo a dicotomia ensino e pesquisa. Assim, torna-se imperativo entender a forma concreta e não abstrata pela qual a formação do professor, centrada na profissionalização, se apresenta. Isso pressupõe ir "além do capital” (MÉSZÁROS, 2007), num 
movimento de contraposição crítica à natureza dessa profissionalização, fundamentada na epistemologia da prática e não da práxis, que delega ao historiador a função de pesquisador e produtor do conhecimento histórico e ao professor a de produtor de um tipo diferenciado de conhecimento, pautado na e voltado para a prática.

\section{A dicotomia pesquisa e ensino no contexto específico da formação do historiador professor}

No interior do quadro de referências explicitado, pode-se levantar a hipótese da existência de um processo de descolamento no interior da dimensão cognitiva da cultura histórica, devido ao processo de especialização da História como ciência, provocando a separação entre quem pesquisa - os historiadores; e quem ensina - os outros.

Segundo Rüsen (2010), a consolidação da História como ciência excluiu a Didática da História do centro da reflexão do historiador sobre sua própria profissão, sendo substituída pela metodologia da pesquisa histórica, provocando uma separação entre o ensino da História e a sua pesquisa. Durante o processo de 'cientifização' da História, o ensino passou a ser visto como atividade de menor valor, secundária, de mera reprodução do saber acadêmico, com objetivo de cumprir as finalidades pressupostas nos processos e formas de escolarização de cada sociedade. Ao ato de ensinar História e ao produto de tal ato não se atribuía o status de ciência, uma vez que, enquanto o conhecimento científico era produzido exclusivamente pelos profissionais da História, a tarefa da didática da História era transmitir este conhecimento sem participar da criação do discurso (RÜSEN, 2010, p. 27). Essa separação acabou deixando um vazio para o conhecimento histórico acadêmico, o vazio de sua função, pois a partir do século dezenove, quando os historiadores constituiram sua disciplina, eles começaram a perder de vista um princípio importante, qual seja, que aquela História precisa estar conectada à necessidade social de orientação da vida dentro da estrutura temporal (RÜSEN, 2010, p. 31). Justificava-se a existência do conhecimento histórico erudito para que esse servisse como base para o ensino, todavia, não se justificava o ensino da História, porque sua função para a vida prática havia se perdido. Essa desconexão da disciplina História, de um sentido prático, se por um lado ofereceu-lhe o status de disciplina erudita, por outro, gerou o vazio da função do ensino de História na escola. Tal ponto de vista chegou ao ápice em meados do século XX, momento em que a História formal não se direcionou diretamente a essência do conhecimento histórico escolar. Os historiadores consideraram que sua disciplina podia ser legitimada pela mera existência e os estudos históricos e sua produção de conhecimento foram comparados a uma árvore que produz suas folhas: "A árvore vive contanto que tenha folhas e é seu destino viver e ter folhas". "Recusou-se a dar para História qualquer uso prático ou real função nas áreas culturais onde a História pode servir como um meio para fornecer explicitamente uma identidade coletiva e para uma orientação para vida"(RÜSEN, 2010 p. 34).

Gradativamente, a separação entre a Didática da História e a História acadêmica foi contribuindo para a formação de um "código disciplinar" próprio da História (FERNANDEZ, 1998), o que empurrou as questões do ensino e aprendizagem da História para o âmbito da cultura escolar. A partir desse reajustamento, a dimensão cognitiva da história passou a se articular com a dimensão política da cultura histórica. 
Nesse processo, as questões relacionadas à aprendizagem histórica e, portanto, ao seu ensino, saíram da pauta dos historiadores e entraram, prioritariamente, na pauta das teorias e políticas educacionais e, portanto, das formas e funções da escolarização. Em decorrência, o elemento político da cultura histórica passa a ser orientado pelas finalidades das políticas educacionais e, portanto, crivado essencialmente pelos interesses e determinações das relações de poder hegemônicos.

Com relação ao significado da função do historiador professor, a divisão do trabalho já se encontra explicitada desde os primeiros documentos oficiais relacionados à sua formação, como se observa no Parecer 292, de 14 de dezembro de 1962, conhecido também como Parecer Valnir Chagas (nome do seu relator). Nesse documento, aparece a separação entre as disciplinas de conteúdo específico e as disciplinas pedagógicas destinadas à formação do professor. Foi atribuído um cunho notadamente instrumental às disciplinas pedagógicas e a natureza do ensino foi pensada como uma tarefa de aplicação dos conteúdos específicos, para a qual o futuro professor deveria ser treinado, por meio da prática de ensino e do estágio.

A Prática de Ensino deve ser feita nas próprias escolas da comunidadade, sob a forma de estágios, como "internatos" dos cursos de Medicina. Só assim poderão os futuros mestres realmente aplicar os conhecimentos adquiridos, dentro das possibilidades e limitações de uma escola real, e ter vivência do ato docente. (BRASIL, 1962, apud URBAN, 2009, p. 54).

Segundo Urban (2009) os aspectos mais ressaltados nesse Parecer são: a preocupação com um ensino focado no aluno, perspectiva muito presente na teoria pedagógica do período, que tem como referência o ideário escolanovista; o grande valor atribuído à Didática, pensada em termos de métodos e práticas de ensino, "Nesse sentido, aluno e método são as palavras-chave que nortearam essa legislação pertinente à formação do professor, em que a prática de ensino, aliada à Didática e somada à Psicologia, constituíram um tripé fundamental [...]” (URBAN, 2009, p. 54-55).

Em 1986, portanto, praticamente 25 anos após a implantação do Parecer Valnir Chagas, a Secretaria de Ensino Superior - SESU-MEC solicitou a um grupo de historiadores que fizesse um diagnóstico dos cursos de história no Brasil. O relatório destaca, com ênfase, a importância da prática de ensino se localizar nos Departamentos de História. Constatada a dicotomia entre a formação do historiador professor e o historiador pesquisador, os autores sugerem, como solução:

1. Não é suficiente que a prática de ensino seja lecionada por professores com licenciatura em História; é preciso uma presença real e permanente do Departamento nessa matéria;

2. Há necessidade de maior entrosamento entre os Departamentos de História e os Departamentos ou Faculdades de Educação (debates, encontros, seminários, presença recíproca de docentes nos Departamentos), pois há um longo caminho a percorrer ainda em função do conflito entre as concepções de História vigentes entre os historiadores e os pedagogos. (MEC/SESu, 1986, apud URBAN, 2009 p. 57). 
Nesses documentos se observa a manutenção da divisão do trabalho que foi instituída no e pelo processo histórico de constituição da História como conhecimento científico, no contexto da expansão da escolarização nas sociedades capitalistas ocidentais. Sendo lacunar a esse respeito, principalmente no documento diagnóstico, se observa uma saída pragmática, com a assunção das disciplinas relativas ao ensino pelos próprios historiadores nos Departamentos de História. Esse diagnóstico foi um dos documentos que alimentou o Parecer 492/2001, que propôs a reformulação curricular para os cursos de formação de professores no Brasil.

É preciso levar em conta que o Parecer 492 faz parte de um conjunto de leis, diretrizes curriculares, programas do governo brasileiro (como o PNLD), nos quais estão embutidas reformas educacionais iniciadas na década de 1990 e que

\begin{abstract}
tais reformas se articulam com base em interesses comuns, com proposições de Organizações Multilaterais (OM) que se tem destacado na coordenação e formulação de um conjunto de políticas educacionais para o mundo [...]. Partilhando interesses burgueses com diversos países, as OM, via diferentes táticas, estabelecem metas, definem setores prioritários e estratégicos e organizam a execução de sua agenda a médio e longo prazo. (EVANGELISTA; TRICHES, 2013).
\end{abstract}

O documento do Banco Mundial Education Sector Strategy Update (ESSU): Achieving Education For All, Broadening Our Perspective, Maximizing Our Effectiveness, publicado em 2006, atualiza as orientações e prognósticos para a relação educação e desenvolvimento nos países emergentes, particularmente como fator de redução da pobreza, já publicizados por esse Banco, em 1990. Além de defender uma política de resultados e a cultura da avaliação, um dos problemas apontados nos estudos realizados pelas OM (Organizações Multilaterais) foi o do déficit de professores. Assim, uma das metas estabelecidas para 2015 foi a de atrair mais professores e formá-los a baixo custo, isto é, profissionalizar o professor.

Nesse mesmo contexto, e conforme o trabalho publicado com o título "Agenda Globalmente Estruturada para a Educação", de Roger Dale (2004), a categoria da profissionalização foi eleita como um dos pilares das reformas educacionais e ganhou muitos adeptos. Segundo Shiroma e Evangelista (2011), esta acolhia reivindicações relacionadas, não só à formação profissional baseada no desenvolvimento de competências para exercer um ofício, auferidas por instituições credenciadas e de ensino superior, como também aquelas relacionadas a carreira, salários e formação de conselhos que confeririam o direito ao exercício profissional. A perspectiva da profissionalização está presente na LDB 9394/96, quando cria a denominação "profissionais da educação" e orienta diretrizes e reformas educacionais a partir da década de 1990.

Os reformadores insistiam na necessidade de adequar o currículo e o professor à realidade, alegando-se o anacronismo de ambos, destacando a sua inadequação às exigências do mundo moderno, às demandas de novas habilidades e competências demandas pelo mercado de trabalho. Desqualificavam os cursos universitários de formação docente, apontados como longos, essencialmente teóricos e pouco flexíveis. (SHIROMA; EVANGELISTA, 2011, p. 130). 
$\mathrm{Na}$ perspectiva apontada por Dale (2004), no contexto da globalização que hipervaloriza os dispositivos articulados à manutenção do sistema capitalista, em detrimento de outras possibilidades e princípios, não é descartada a construção do consenso em nome da governabilidade e a política educacional é transvestida como solução para a democratização dos bens culturais, ao acesso ao conhecimento e à informação, o que demanda a reconversão profissional do professor - de um professor tradicional para inovador; de acomodado para criativo; de desmotivado para aprendiz contínuo; de teórico para competente na prática.

A profissionalização centrada na competência prática encontra-se explicitamente demarcada no Parecer 492/2001, com a expansão do número de horas exigidas para a formação prática do historiador professor, provocando interrogações e contestações em alguns membros da academia. $\mathrm{Na}$ mesma perspectiva da centralidade na profissionalização pela prática, estão os Referenciais Curriculares Nacionais dos Cursos de Licenciatura e Bacharelado, divulgados pela SESU/MEC, em abril de 2010 (BRASIL, 2010) . De início, em sua Introdução, o documento propõe uma relação orgânica entre a educação da população brasileira e o desenvolvimento tecnológico do país.

A elevação da escolaridade, para qualquer país contemporâneo, representa elevação dos padrões sociais, pela consolidação cultural, melhoria da qualidade de vida, inclusão social e maior liberdade de construção dos destinos de cada cidadão. No Brasil isto não é diferente. Â medida que a elevação da escolaridade se consolida, todos os indicadores sociais se elevam. O ensino superior, por seu turno, tem duplo papel no desenvolvimento social: além da construção da cidadania pela formação de profissionais bem qualificados, para os desafios da crescente complexidade tecnológica presente em todas as áreas da atividade humana, deve também buscar soluções inovadoras. (BRASIL, SESu/MEC, 2010).

Tendo em vista o contexto em que foi proposta, bem como os princípios da profissionalização nela inerentes, a dicotomização bacharelado e licenciatura é assumida como proposta oficial, sendo que a licenciatura pode ser reduzida à uma formação de 3 anos (o bacharelado é 4).

À moda do historiador, podem ser construídas perguntas a essas diretrizes, no sentido de se procurar entender, informar, descrever, seja que objetivo for proposto, no que tange à questões como: que historiador se pretende formar? Para que? Qual ou quais os compromissos do historiador bacharel e/ou licenciado? Para essas perguntas não há respostas, a não ser aquelas de ordem instrumental do tipo - o bacharel serve para atuar em... o licenciado serve para atuar em... Assim, não se consegue nem deduzir qual é a concepção de "historiador pesquisador" e de "historiador professor", e para que sociedade, com quais finalidades ele é formado. No entanto, parecem estar explícitas concepções de "historiador pesquisador e historiador professor" bem diferenciadas. Para um, uma formação num tempo maior, com mais conteúdos específicos da ciência; para outro, uma formação num tempo menor, apesar de com mais horas e com uma diversificação de disciplinas de cunho instrumental, mostrando, como afirmam Evangelista e Shiroma (2007), uma restrição nos conteúdos da formação docente, centrados numa perspectiva de saber instrumental, e um alargamento das funçôes docentes [...]. Manifesta-se 
a preocupação com a eficiência e eficácia do trabalho docente, inseridas numa lógica racionalizadora, técnica, pragmática (2007, p. 536). Essa perspectiva instrumental, baseada na lógica racionalizadora, técnica e pragmática, tem imposto a primazia da docência como ação em detrimento do professor como sujeito (EVANGELISTA; SHIROMA, 2007). É nessa lógica que a prática encontra seu lugar e conquista a adesão, pelo consenso, por meio de propostas curriculares, projetos de avaliação e de cursos de formação de professores de História ou, como afirmam, ainda, Evangelista e Shiroma

As providências concretas para o exercício do controle político-ideológico sobre o magistério envolvem sua formação e sua atuação profissional. Ou seja, a reforma dos anos 1990, e seu prosseguimento no novo século, atingiu todas as esferas da docência: currículo, livro didático, formação inicial e contínua, carreira, certificação, lócus de formação, uso das tecnologias da informação e comunicação, avaliação e gestão. (EVANGELISTA; SHIROMA, 2007, p. 537).

\section{Epistemologia da prática e o lugar do historiador professor: que história é essa?}

A análise das fontes documentais relacionadas às propostas de orientações das políticas educacionais, no período 1990/2010, tem permitido aferir a presença da ideia de profissionalização com ênfase na prática. Tal perspectiva pode ser antevista em situações específicas que envolvem, inclusive, concepções de aprendizagem que fundamentam as diferentes esferas da cultura escolar, como indicado por Evangelista e Shiroma (2007).

Nesse contexto, e tendo como norte as considerações apresentadas, realizou-se a análise da Resolução 03/1998, do Conselho Nacional de Educação, que tem fundamentado as diretrizes curriculares, inclusive as de História. Entre outras questões, esse documento, de autoria da conselheira Guiomar Namo de Mello, propõe a contextualização como princípio pedagógico que define a maneira de organização e tratamento dos conteúdos curriculares.

O tratamento contextualizado do conhecimento é o recurso que a escola tem para retirar o aluno da condição de espectador passivo. Se bem trabalhado permite que, ao longo da transposição didática, o conteúdo de ensino provoque aprendizagens significativas que mobilizam o aluno e estabeleçam entre ele e o objeto de conhecimento uma relação de reciprocidade [...]. (BRASIL, CNE/CEB, 1998, p. 37).

A adoção desse princípio, segundo a própria relatora Guiomar Namo de Mello (BRASIL, 1998), deve-se à inadequação histórica dos programas e manuais didáticos, no caso específico, do Ensino Médio, à realidade dos jovens, às suas experiências cotidianas - O contexto que é mais próximo do aluno e mais facilmente explorável para dar significado aos conteúdos da aprendizagem é o da vida pessoal, cotidiano e convivência (BRASIL, CNE/CEB, 1998). Opondo-se à ideia de contextualização sugerida no documento, Kuenzer (2000) aponta algumas considerações. Em primeiro lugar, segundo essa autora, 
o cotidiano não se explica em si, mas através da história que é feita por homens e mulheres reais, que estabelecem relações entre si e com o mundo através do trabalho em sua dimensão de práxis humana; relações que são de exploração ou de solidariedade, de submissão ou de dominação, em face da diferente distribuição dos meios responsáveis pela produção da riqueza e, em consequência, do conhecimento. (KUENZER, 2000, p. 74).

Assim, continua Kuenzer, torna-se necessário precisar de que cotidiano se fala, bem como do significado que terá, em função dos lugares sociais contraditórios ocupados pelos diferentes sujeitos. Em segundo lugar, para Kuenzer:

Da mesma forma, nem tudo o que precisa ser aprendido pode ser contextualizado, em face do caráter histórico da produção científica. Se tomarmos esse conceito com relação à realidade imediata ou à praticidade, essa forma de conceber a educação a reduziria a uma versão utilitarista. [...] O que e como ensinar de forma contextualizada, portanto, definem-se antes pelas finalidades a atingir do que pelo imediatismo ou pelas necessidades práticas postas por um contexto supostamente neutro. Essas finalidades dizem respeito a pessoas concretas que vivem em situações reais que precisam ser compreendidas em si e em suas articulações com a totalidade da vida social. (KUENZER, 2000, p. 74-75).

O entendimento relativo ao princípio pedagógico da contextualização, como a capacidade do aluno relacionar e/ou aplicar o conhecimento às situações da vida cotidiana, presente no documento orientador dos parâmetros curriculares nacionais para o ensino médio, tem como fundamento, como explicitado pela relatora do documento, a concepção de "aprendizagem situada". Segundo Lopes,

O documento oficial afirma explicitamente que esse conceito se fundamenta em David Stein e sua idéia de uma aprendizagem situada (Brasil, 1999, v. 1, p. 141-142), com base na vivência de situações do dia-a-dia, segundo os interesses dos alunos, e no desenvolvimento de atividades desvinculadas da pura transmissão de conceitos. Para Stein (1998), situar uma aprendizagem significa colocar o pensamento e a ação em um lugar específico de significado, envolver os aprendizes, o ambiente e as atividades para produzir significado. Todo conhecimento é construído de forma situada, em determinado contexto, de maneira a ser transferido para situações similares. (LOPES, 2002, p. 7).

Com relação a esses pressupostos, são elucidadoras as reflexões de Boron (2001) sobre o "artificial pratiquismo", caracterizado pela presença de um certo entrave antiteórico do saber convencional, potencializado pelas exigências do mercado de trabalho e que premia atitudes pragmáticas e realistas, e castiga o espírito crítico e a inclinação teórica.

Ao marco teórico baseado na concepção de aprendizagem situada e no princípio da contextualização, presente na proposta para o Ensino Médio, agrega-se a orientação para o ensino baseado no desenvolvimento de competências. Essa perspectiva foi introduzida no Brasil na década de 1990, por meio da chamada "Pedagogia das Competências", e está bem explicitada nos Parâmetros Curriculares para o Ensino 
Médio, anunciada por meio de diferentes tipos de competências, como as competências cognitivas complexas (autonomia intelectual, criatividade, solução de problemas, análise e prospecção); competências de tipo geral (capacidade de continuar aprendendo) e competências cognitivas básicas (raciocínio abstrato, capacidade de compreensão de situações novas). Destacam-se, também, as competências de caráter geral para a inserção no mundo do trabalho. Ao mesmo tempo, a implantação do ensino por competências veio acompanhada da imposição da avaliação de resultados, o que acabou por instalar uma lógica burocrática nos sistemas de ensino, voltada para tais aferiçôes e comparaçôes com padrões internacionais (ALMEIDA, 2009, p. 88).

Um dos maiores problemas causados pela adoção da pedagogia das competências é o fato de que o conhecimento específico deixa de ser referência para a aprendizagem e o ensino, acabando por serem valorizadas determinadas atividades destinadas a desenvolver competências estabelecidas a priori, e elas constituem modalidade de governo político das práticas de ensino, desqualificando as dimensóes formativas dos saberes constituídos (ALMEIDA, 2009, p. 97). Na mesma direção, concorda-se com Kuenzer (2002), que são essas dimensões formativas que constituem o centro do processo de escolarização, o que a diferencia de outros espaços como aqueles adstritos ao trabalho profissional e que respondem às demandas de determinadas práticas específicas. Foi isso que a autora constatou em sua pesquisa com trabalhadores de plataformas de petróleo. Nos resultados dessa investigação, Kuenzer apreendeu a importância que estes dão ao desenvolvimento de determinadas competências necessárias ao mundo do trabalho. No entanto, diz a autora:

A escola é o lugar de aprender a interpretar o mundo para poder transformá-lo, a partir do domínio das categorias do método e de conteúdos que inspirem e que se transformem em práticas de emancipação humana em uma sociedade cada vez mais mediada pelo conhecimento. O lugar de desenvolver competências, que por sua vez mobilizam conhecimentos mas que com eles não se confundem, é a prática social produtiva [...] Cabe às escolas, portanto, desempenharem com qualidade seu papel na criação de situações de aprendizagem que permitam ao aluno desenvolver as capacidades cognitivas, afetivas e psicomotoras relativas ao trabalho intelectual, sempre articulado, mas não reduzido ao mundo do trabalho e das relações sociais [...] Atribuir à escola a função de desenvolver competências é desconhecer sua natureza e especificidade enquanto espaço de apropriação do conhecimento socialmente produzido e, portanto, de trabalho intelectual com referência à prática social[...]. (KUENZER, 2002, p. 8).

Configura-se, assim, uma perspectiva pragmática de conhecimento em que o conhecimento individual é reduzido à percep̧̧ão imediata e a saberes tácitos. Estamos perante uma teoria do conbecimento como fenômeno cotidiano, particular, idiossincrático e não assimilável pela racionalidade cientifica. (DUARTE, 2000, apud SCALCON, 2008), e os documentos que têm fundamentado as propostas de formação do historiador professor, bem como de sua atuação profissional, são indiciários desse "pragmatismo epistemológico" (SCALCON, 2008). Da mesma forma, essa perspectiva tem encontrado guarida em determinados autores, considerados referências para a formação de professores no Brasil. Nessa direção, cabe citar os conceitos de "epistemologia da prática 
profissional - um conjunto dos saberes realmente utilizados pelos profissionais (professores) em seu espaço de trabalho cotidiano para desempenhar todas as suas tarefas (TARDIF, 2002, p. 225), bem como o de "prática reflexiva" (PERRENOUD, 2002) - segundo o qual os professores, a partir de sua própria prática, são capazes de realizar reflexões e produzir saberes relacionados à sua profissão, indicando a centralidade na aquisição de competências e não de conhecimentos científicos e teóricos que, no afã de sobrevalorizar a experiência cotidiana dos professores em seu espaço de trabalho, as imprecisôes e incongruências peculiares a tal epistemologia da prática os tolhe em sua capacidade de capturar as relaçôes funcionais dos fenômenos empiricos (MORAES, 2004, p. 10).

Em artigo publicado no ano de 2007, com o título "Propuestas para elnuevo paradigma educativo de la historia", o historiador e pesquisador da Universidade de Santiago de Compostela, Carlos Barros anuncia que está se impondo, "a partir de cima”, a formação de um novo paradigma para a formação do professor de História, convergente em vários aspectos e específico a partir de sua adequação em cada país. Para esse autor, esse novo paradigma tem tido uma acolbida explícita em muitos setores acadêmicos latino-americanos e também implícito de ordem administrativa na Europa, como mostra o polêmico e importante projeto para o Ensino Superior "Tuning Educacional Structures in Europe" e a recomendação categórica da União Européia a favor da educação por competências (BARROS, 2007, p. 3). A consolidação de propostas para formação do historiador professor em mestrados não acadêmicos é uma das tônicas desse projeto, constituindo um braço do chamado Acordo de Bolonha, de 1999. Trata-se de um documento produzido pela Confederação Européia das Conferências de Reitores e pela Associação Européia de Universidades que propõe, entre outros, a organização de um sistema educacional que permita a mobilidade de professores e estudantes, como também a empregabilidade, para tanto pressupõe uma organização de cursos superiores compativeis em todas as universidades [...] (URBAN, 2009, p. 129).

$\mathrm{Na}$ Espanha e em Portugal, as orientações do Projeto de Bolonha causaram, de forma concreta e explícita, a criação dos mestrados profissionais a partir dos quais os historiadores são gabaritados a atuarem como "docentes" na escola básica. Nesses dois países, esses mestrados apresentam uma base comum e uma base diversificada, para atender às especificidades locais.

\section{Considerações finais}

Inscrito nas determinações históricas que construíram objetivamente os percursos da História como ciência e os diálogos entre a cultura histórica e a cultura escolar, a unidade necessária entre a teoria e a prática, a ciência e a vida, constitutiva da formação do professor historiador, foi sendo desconstruída e rompida, enredada em processos muitas vezes contraditórios aos próprios desígnios da ciência da História.

Explicitar os embates e dilaceramentos que habitam a profissão do professor historiador possibilita compreendê-los em seus limites e possibilidades, negatividade e positividade de uma utopia como desassossego que, de um lado evoca uma inquietação, uma irritação com o historicamente dado e determinado; de outro evoca um movimento em direção a um horizonte pleno de vitalidade. Poderia, como afirmou 
Bloch, terminar essas reflexões dizendo - Caros Amigos - Como sabeis, sou professor de história, o passado constitui a matéria do meu ensino (1998, p. 21). Sim, essa seria uma boa resposta à problematização inicial. Mas, como a história nos mostra, vivemos momentos de manifestações e inquietações e precisamos construir o presente, perspectivando o futuro com cuidado, evitando o perigo de que os elementos da utopia deixem de ser pervertidos em instrumentos de poder e violência, para transformá-los em elixir de nossa visão crítica das atuais condições de desenvolvimento do mundo. Sendo assim, poderia revisitar Bloch (1998, p. 21), buscando responder a pergunta - professor de história, que historiador é esse? - dizendo - Caros amigos sou um professor de bistória desassossegado. Se o tempo passado é minha matéria de ensino, a ele recorro para suprir as carências do presente e perspectivar o futuro, utopicamente.

\section{Referências}

ALMEIDA, M. I. Professores e competência - Revelando a qualidade do trabalho docente. In. ARANTES, V. A. (Org.). Educação e competências. São Paulo: Summus, 2009, p. 77-122.

BARROS, C. Propuestas para el nuevo paradigma educativo de la historia. In: Revista HISTEDBR On-line, Campinas, n. 28, p. 2-24, dez. 2007.

BITTENCOURT, C. (Org.). O saber histórico na sala de aula. São Paulo: Contexto, 1998.

BLOCH, M. História e Historiadores. Lisboa: Teorema, 1998.

BORON, A. A coruja de Minerva. Mercado contra democracia no capitalismo contemporâneo. Rio de Janeiro: Vozes, 2001.

BRASIL/MEC/SESu. Referenciais Curriculares Nacionais dos Cursos de Bacharelado e Licenciatura. Brasília: MEC/SESu, abril 2010.

BRASIL. CNE/CEB. Diretrizes para o Ensino Médio. Parecer n. 15, jun. 1998. Disponível em: <www.cefetce.br/Ensino/Cursos/Medio/parecerCEB15htm>. Acesso em: 28 maio 2013.

DALE, R. Globalização e educação: demonstrando a existência de uma "Cultura Educacional Mundial Comum" ou localizando uma "Agenda Globalmente Estruturada para a Educação"? In: Revista Educação \& Sociedade. Dossiê Globalização e Educação: Precarização do trabalho docente. Campinas, v. 25, n. 87, maio/ago. 2004. Disponível em: <http://dx.doi.org/10.1590/ S0101-73302004000200007>. Acesso em: 10 jun. 2013.

EVANGELISTA, O.; TRICHES, J. (Org.). Professor: a profissão que pode mudar um país? In. EVANGELISTA, O. (Org.). O que revelam os slogans na política educacional. [S.1.: s.n.], 2013.

EVANGELISTA, O.; SHIROMA, E. O. Professor: protagonista e obstáculo da reforma. In: Revista Educação e Pesquisa. São Paulo, v. 3, set./dez. 2007, p. 531-543.

FERNANDEZ, R. C. Clio en las aulas. La enseñanza de la Historia en España entre reformas, ilusiones y ruinas. Madrid: Akal, 1998.

KUENZER, A. Ensino Médio: Construindo uma proposta para os que vivem do trabalho. São Paulo: Cortez, 2000.

Conhecimento e competencia no trabalho e naescola. Boletim Técnico do Senac. Rio de Janeiro, v. 28, n. 2, p. 3-11, ago. 2002. Disponivel em: <www.senac.br/BTS/282/boltec282a >. Acesso em 12 de abril de 2013.

LOPES, A. C. Os Parâmetros Curriculares Nacionais para o Ensino Médio e a submissão ao mundo produtivo: o caso do conceito de contextualização. In: Revista Educação e Sociedade. Campinas, v. 23 , n.80, nov./2002, p. 386-400. 
MÉSZÁROS, I. O desafio e o fardo do tempo histórico. São Paulo: Boitempo, 2007.

MORAES, M. C. M. Proposição acerca da produção de conhecimento e políticas de formação docente. In: MORAES, M. C. M. (Org.). Iluminismo às Avessas. Produção de conhecimento e políticas de formação docente. Rio de Janeiro: DP \& A, 2003, p.7-19

PERRENOUD, P. A prática reflexiva no ofício do professor: profissionalização e razão pedagógica. Porto Alegre: ARTMED, 2002.

RÜSEN, J. Didática da História: passado, presente e perspectivas a partir do caso alemão. In: SCHMIDT, M. A.; BARCA, I.; MARTINS, E. R. (Orgs.).Jörn Rüsen e o ensino de História. Curitiba: Editora da UFPR, 2010.

SCALCON, S. O pragmatismo epistemológico e a formação do professor. In: Revista PerCursos. Florianópolis, v. og., n. 02, ano 2008, p. 35-49.

SCHMIDT, M. A. A formação do professor de história e o cotidiano da sala de aula. In: BITTENCOURT, C. op. cit., 1998, p. 54-68

SHIROMA, E. O.; EVANGELISTA, O. Avaliação e responsabilização pelos resultados: atualizações nas formas de gestão de professores. In: Revista Perspectiva. Florianópolis, v. 29, n. 1, jan./jun. 2011, p. 127-160.

TARDIF, M. Saberes docentes e formação profissional. Petrópolis, RJ: Vozes, 2002.

URBAN, A. C. Didática da História: percursos de um código disciplinar no Brasil e na Espanha. Curitiba: Programa de Pós-Graduação em Educação da Universidade Federal do Paraná, 2009. (Tese de doutorado).

* Professora doutora da Universidade Federal do Paraná, Curitiba, Paraná, Brasil.

\section{Correspondência}

Maria Auxiliadora Moreira dos Santos Schmidt - Rua Dr. Nelson de Souza Pinto, 709 - CEP 82200-

060 - Curitiba, Paraná, Brasil.

E-mail: mariaschmidt@gmail.com

Recebido em 02 de junho de 2015

Aprovado em 08 de junho de 2015 